\title{
Influence of the Yangtze River and grain size on the spatial variations of heavy metals and organic carbon in the East China Sea continental shelf sediments
}

\author{
Saulwood Lin ${ }^{\text {a, * }}$, I-Jy Hsieh ${ }^{\text {a }}$, Kuo-Ming Huang ${ }^{\text {a }}$, Chung-Ho Wang ${ }^{\text {b }}$ \\ a Institute of Oceanography, National Taiwan University, Taipei, Taiwan \\ ${ }^{\mathrm{b}}$ Institute of Earth Sciences, Academia Sinica, Taipei, Taiwan
}

Received 30 August 2000; accepted 9 May 2001

\begin{abstract}
Bulk heavy metal $(\mathrm{Fe}, \mathrm{Mn}, \mathrm{Zn}, \mathrm{Cu}, \mathrm{Pb}, \mathrm{Cd}), \mathrm{Al}$, organic carbon and carbonate concentrations, grain sizes, and $\delta \mathrm{C}^{13}$ of the organic carbon distributions were studied in sediments collected throughout the East China Sea continental shelf and the Yangtze River Delta. The results demonstrated that terrigenous sediments from the Yangtze River is a dominating factor controlling the spatial variations of heavy metals and organic carbon concentrations on the East China Sea continental shelf. In addition, grain size and recent anthropogenic influences are also major factors modifying the spatial and vertical variations of heavy metals.

Large spatial variations with a band type distribution of heavy metals, grain size, organic carbon and carbonate were observed. Higher concentrations of heavy metal and light $\delta \mathrm{C}^{13}$ of the organic carbon were found primarily in the Deltaic and inner shelf sediments. The band type distribution generally followed the coastline with little variations in the north-south direction. Away from the Delta and inner shelf (west-east direction), most heavy metal concentrations decreased rapidly with the exception of $\mathrm{Cd}$ where high concentrations of $\mathrm{Cd}$ were also found in the carbonate-rich shelf break sediments. Coarse-grained relict sediments and biogenic carbonate are two primary diluting agents for the fine-grained aluminosilicate sediments from the Yangtze River with high concentrations of heavy metals.

Unusually high concentrations of $\mathrm{Cu}, \mathrm{Pb}$, and $\mathrm{Cd}$ showed both spatially and vertically that more pollution prevention measures are needed in the Yangtze River drainage basin in order to prevent further heavy metal pollution of the East China Sea inner continental shelf. (c) 2002 Elsevier Science B.V. All rights reserved.
\end{abstract}

Keywords: Yangtze River; East China Sea; Continental Shelf; Sediments; Heavy metal

\section{Introduction}

Yangtze River is the largest river in China and one of the largest in the world. After nearly three decades of economic reform and booming industrial

\footnotetext{
* Corresponding author. Tel./fax: +886-2-23636424.

E-mail address: swlin@ccms.ntu.edu.tw (S. Lin).
}

development, a tremendous amount of both natural and anthropogenic heavy metals was carried by the River into the East China Sea continental shelf. The annual discharge of suspended particle is approximately $480 \times 10^{6}$ tons/year (Milliman and Meade, 1983). Together with these tremendous amounts of suspended sediments, a great deal of terrigenous organic matter and heavy metals associated with 
aluminosilicate were also transported out into the shelf. Understanding their deposition on the continental shelf is essential in determining the fate of terrigenous materials from the river. Large rivers such as the Yangtze River are particularly important as a major source of terrigenous material exporting to the ocean (Milliman and Meade, 1983; Milliman and Syvitski, 1992). DeMaster et al. (1985) estimated that approximately $50 \%$ of the suspended particle were transported and dispersed south of the Yangtze River Delta. However, Niino and Emery (1961) showed that a great majority of East China Sea continental shelf sediments were relict sediments from the last glacial. Despite the considerable efforts devoted to the study of the Yangtze River (see Luo and Ostenso, 1983; Yu et al., 1990), data regarding the exact extent and deposition of recent sediments from the River on the East China Sea continental shelf remained inconclusive since most investigations had focused on deposition processes near the Yangtze River Delta.

In addition to the tremendous amount of natural terrigenous material carried by the Yangtze River, recent rapid industrial development in China at the expense of environment may also play a very important role on the distribution of heavy metals and a potential ecological consequence on the East China Sea continental shelf. More than one-third of the heavily populated metropolitan areas were located inside the Yangtze River drainage basin. The sheer size of the population compounded with a very fast economic development will likely change the natural distribution processes on the East China Sea continental shelf. In fact, anthropogenic influences on the heavy metal deposition near the Yangtze River Delta were observed in recent studies (Huh and Chen, 1999; Zhang, 1999).

Despite the growing interest in the study of the Yangtze River, our understanding of the influence of Yangtze River on the East China Sea continental shelf is still limited to the region near the river mouth, and little is known concerning the extent and scale of this rapid growing anthropogenic influence on the heavy metals distribution of the East China Sea continental shelf. In order to study the influence of Yangtze River on the East China Sea, a set of sediment samples cover most of the East China Sea continental shelf were collected and analyzed. This study examined the spatial distributions of heavy metals, organic carbon and the stable carbon isotope in the East China Sea continental shelf sediments, and analyzed the major factors controlling the spatial and vertical variations of sedimentary heavy metals. The primary goal of this study was to investigate the influence and the extent of heavy metals from the Yangtze River on the East China Sea continental shelf. In addition, this study also attempted to evaluate the effect and scale of potential heavy metal pollution from the River on the East China Sea continental shelf.

\section{Study area and methods}

\subsection{Study area}

East China Sea is one of the world's largest continental shelf systems. Major sources of terrigenous sediments include the Yangtze $\left(480 \times 10^{6}\right.$ tons /year) and the Huanghe $\left(1100 \times 10^{6}\right.$ tons /year $)$ rivers (Milliman and Meade, 1983). Fine-grained sediments originating from the Huanghe river deposited not only on the Yellow Sea but also on the northern part of the East China Sea (Kim et al., 1998; Lee and Chough, 1989). For the Yangtze River, approximately $40 \%$ of the total suspended loads were deposited in the Yangtze River estuary (Milliman et al., 1985). According to Milliman et al. (1985), shoreline progradation within the Yangtze estuary during the past 2000 to 3000 years has accounted for less than $5 \%$ of the river's load. Most sediment is temporarily deposited offshore and later resuspended and transported southward by subsequent winter storms (Milliman et al., 1985; McKee et al., 1983; DeMaster et al., 1985). Little information is available concerning the extent and the final deposition of the Yangtze River sediments and associated heavy metals south of the Delta.

\subsection{Sampling and analytical methods}

Sediments samples (Fig. 1) at 130 stations were collected on board R/V Vinogradov using a VanVeen type Grab, and R/V Ocean Researcher I, cruise 293, 322, 456, 499 and 551 with a Sautar type 


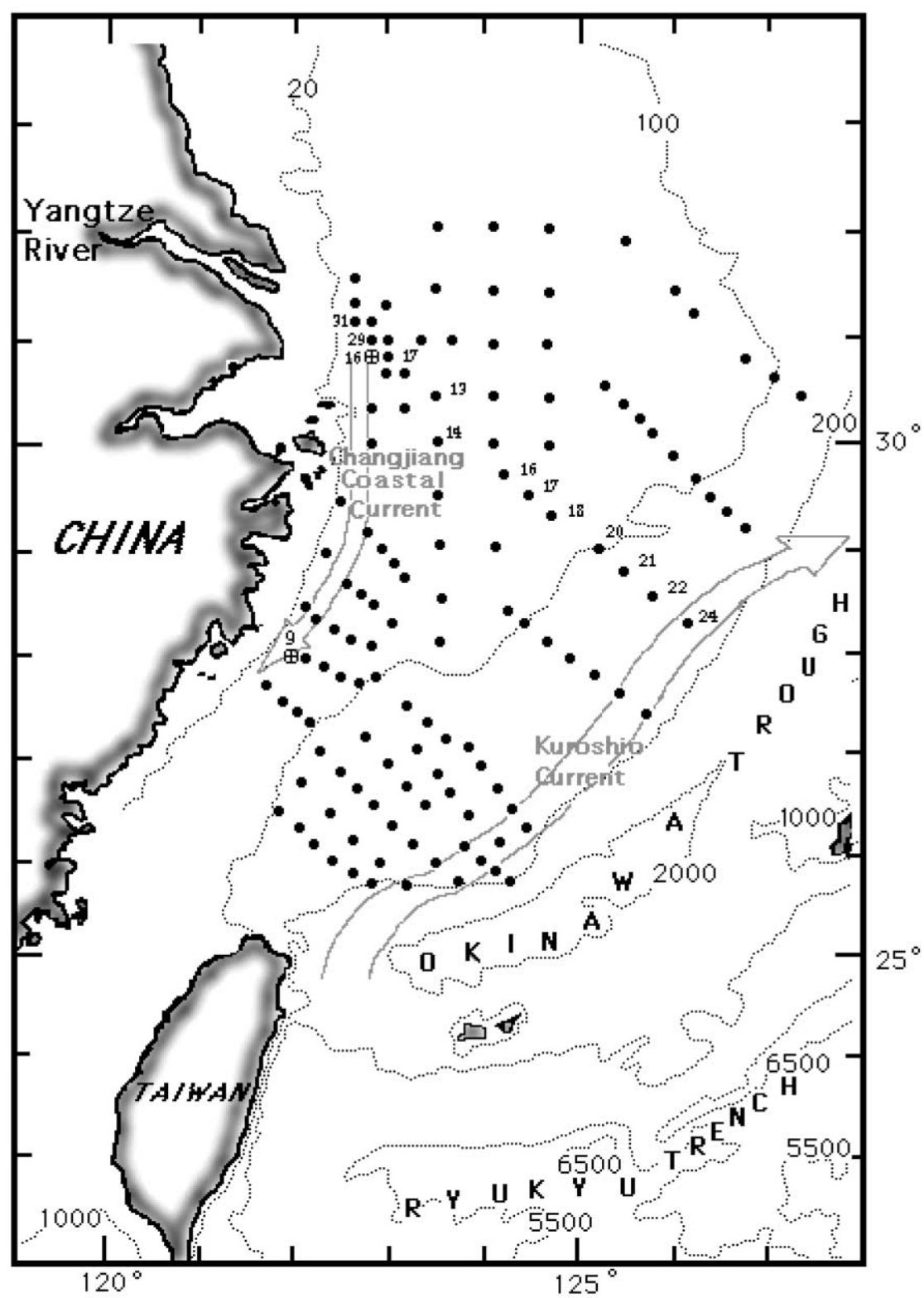

Fig. 1. Study area and sampling stations $(\mathbf{O})$. $\oplus$ : Core locations. Dashed line contours are in meters.

box core and/or Bentho's gravity core. Upon retrieving the core on deck, sediments were subsampled and subcored, sectioned into 1 - to 2-cm sections with a plastic spatula and stored frozen in the polyethylene (PE) bottles.

Sediments were freeze-dried using a Labconco freeze-dryer (Lyph-Lock, 6 1) for 1 week, and then ground to fine powder using an Agate mortar and stored in PE vials. Well-mixed subsamples were analyzed for total metals, inorganic carbon, organic carbon, and $\delta \mathrm{C}^{13}$ of the organic carbon. Untreated sediments were wet sieved through a set of Standard Sieve (Endecotts, England) larger than $63 \mu \mathrm{m}$ to separate the sand size grain. Grain sizes of the 
fraction smaller than the $63 \mu \mathrm{m}$ were determined by the standard pipette technique (Folk, 1974). The precision for the clay (diameter $(d)<4 \mu \mathrm{m}$ ), silt $(4<d<63 \mu \mathrm{m})$ and sand $(d>63 \mu \mathrm{m})$ are $0.37 \%$, $0.96 \%$, and $1.56 \%$, respectively.

Total carbon and organic carbon were analyzed using a LECO C/S Analyzer (SC-444) equipped with a high temperature resistance furnace and an IR detector. Approximately $0.3 \mathrm{~g}$ of dry sediments was combusted at $1400{ }^{\circ} \mathrm{C}$ with high purity oxygen to determine the total carbon content. Organic carbon was determined with pre-acidified $(\sim 2 \mathrm{ml} 6 \mathrm{~N} \mathrm{HCl})$ and later hot-plate dried $\left(\sim 50{ }^{\circ} \mathrm{C}\right)$ sediments. Calcium carbonate content was calculated from the difference between the total carbon and organic carbon content assuming calcite was the only carbonate phase. The precision for the total carbon and organic carbon are $1.2 \%$ and $3 \%$, respectively.

Dry sediments $(\sim 0.25 \mathrm{~g})$ were digested in a Teflon lined digestion vessel using a CEM microwave (MDS-2000) based on Kokot et al. (1992). A mixed reagent (conc. $\mathrm{HNO}_{3} / \mathrm{HF}: 5 / 2$ ) of $2.5 \mathrm{ml}$ was added to each vessel and heated with $100 \%$ power for $10 \mathrm{~min}$. Next, the microwave was set up at $75 \%$ power for $20 \mathrm{~min}$ and $25 \%$ power for $5 \mathrm{~min}$. After the pressure dropped to 1 atm, the digestion vessels were opened and $10 \mathrm{ml}$ of $4 \% \mathrm{H}_{3} \mathrm{BO}_{3}$ were added and the above heating procedures were repeated. Upon completion of the digestion process, the digested solution was stored in PE vials for analyses. A NIST-1646a Standard Sediment was used in each batch digestion for recovery test. Metals (Al, $\mathrm{Fe}, \mathrm{Mn}, \mathrm{Zn}$ : flame; $\mathrm{Cu}, \mathrm{Pb}, \mathrm{Cd}$ : graphite) were determined using Hitachi $8100 \mathrm{Z}$ (graphite) and Perkin-Elmer 3300 (flame) atomic absorption spectrometer. For metals high in concentrations, i.e. aluminum, iron, manganese and zinc, the digestion solution was diluted (5-50 times) with deionized water (Milli-Q, $\sim 18 \Omega$ ) and the concentrations were determined by calibration curves prepared from Merck Standard Metal Solution. For copper, lead and cadmium, the standard addition technique was employed in order to minimize the matrix effect. The accuracy of the metal analysis was determined by total dissolution of the NIST-1646 standard sediment. The analytical precision, as compared to the Standard Sediments, were better than $6 \%$ for most metals except copper and zinc (12\%). Recoveries of 20 replicates analyses of the Standard Sediments were better than $94 \%$ as compared to the reported values.

For organic carbon $\delta \mathrm{C}^{13}$ analyses, sediments were acidified with $1 \mathrm{~N} \mathrm{HCl}$ to remove inorganic carbon. Sealed tube combustion method was used to convert the sediment organic carbon for isotopic analysis (Boutton, 1991). Samples were mixed with $1 \mathrm{~g}$ each of $\mathrm{CuO}$ and $\mathrm{Cu}$ pellets and sealed in evacuated, precombusted $9 \mathrm{~mm}$ quartz tubes. Sample tubes were then combusted in muffle furnace at $900{ }^{\circ} \mathrm{C}$ for $3 \mathrm{~h}$ and $600{ }^{\circ} \mathrm{C}$ for $3 \mathrm{~h}$. After combustion, $\mathrm{CO}_{2}$ samples were cleaned and transferred to $6 \mathrm{~mm}$ glass tubes for $\mathrm{C}^{13}$ analysis. Carbon isotope was analyzed using a SIRA-10 triple-collector mass spectrometer. Calibration was made through analyses of NBS-22. The precision of $\delta \mathrm{C}^{13}$ results was better than $0.06 \%$.

\section{Results}

\subsection{Grain sizes}

Grain sizes display large variations in the East China Sea continental shelf surface sediments. The distribution of sandy sediments (diameter greater than $63 \mu \mathrm{m}$ ) is presented in Fig. 2A. Sand-sized sediments showed a "Band-type" distribution, increasing from the inner shelf minimum to the outer shelf maximum. The sand\% content in sediment varied only slightly in the north-south direction, whereas vast variations were mostly observed in the west-east direction. Near the Delta, grain size showed rapid coarsening effect away from the Delta except in the southward direction where most finegrained sediments were found. As low as $1 \%$ of sand were found in the inner shelf extending from the Yangtze River Delta to the southern end of the study area. This inner shelf consisting primarily of finegrained sediments was very similar to the "mud belt" described by Niino and Emery (1961). In addition, the distribution of fine-grained sediments south of the Delta indicated that most fine-grained sediments from the Yangtze River were transported and later re-deposited southward along the inner shelf.

Sediment grain sizes, in general, showed a rapid coarsening effect from inner shelf to outer shelf. Up to $100 \%$ of sandy sediment were observed in the 

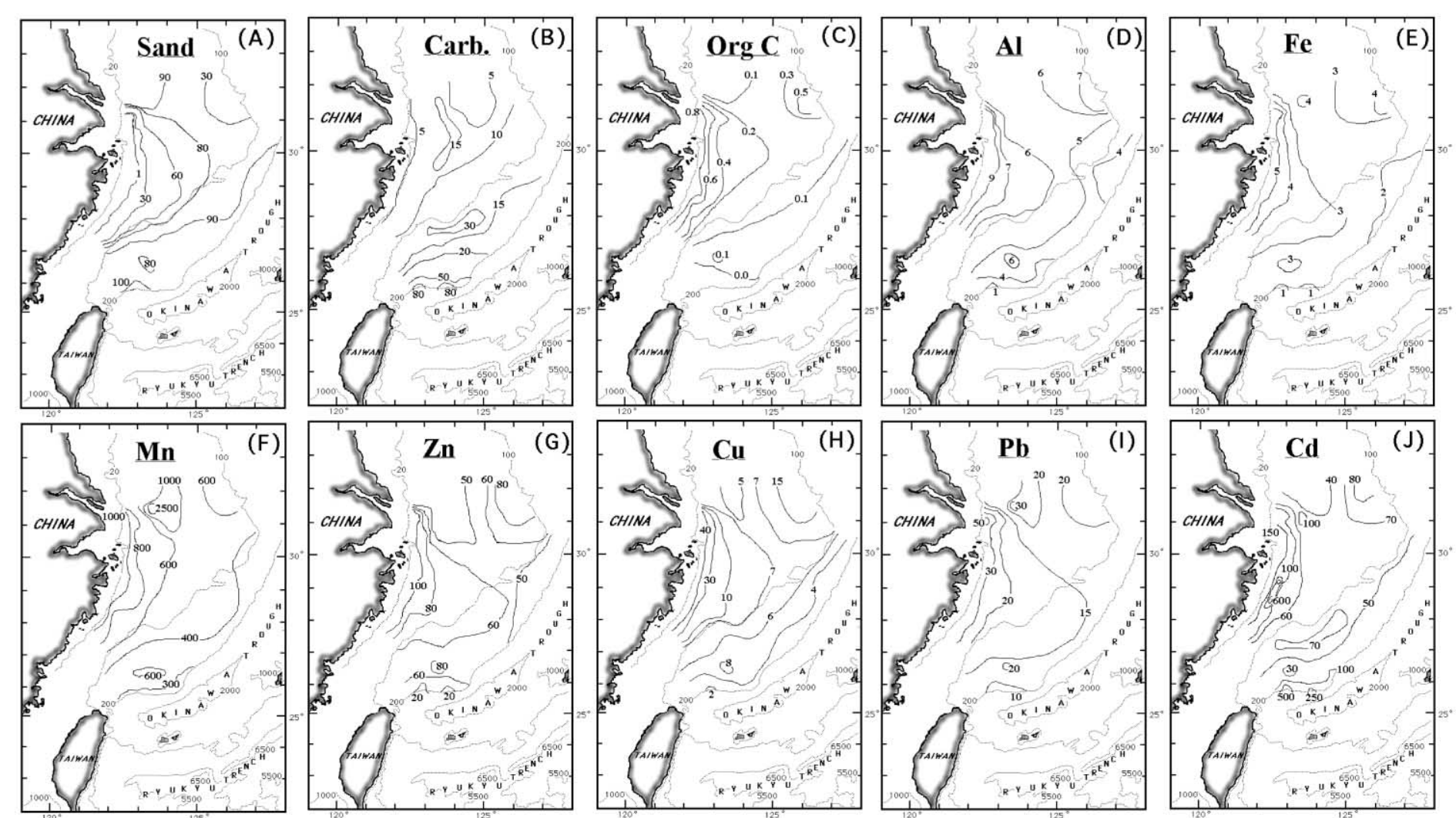

Fig. 2. Distributions of \%Sand, \%Carbonate, \%Organic carbon, aluminum (\%), iron (\%), manganese (ppm), zinc (ppm), copper (ppm), lead (ppm), and cadmium (ppb) in the East China Sea continental shelf surface sediments. 
outer shelf break region as compared to the lowest $1 \%$ in the inner shelf sediments. Sediment grain sizes in the northeastern region of the study area, however, were mostly fine-grained silty clay. Sand-sized quartz was the predominant grain type in most middle and outer continental shelf sediment, whereas carbonate sand was predominant in the southeast part of the outer shelf.

Sediment size distributions of the East China Sea continental shelf also showed vast differences from inner shelf to the outer shelf (Fig. 3). Grain size changes are especially rapid near the Delta. The predominant sediment size of the Delta (e.g. Station 499-31, 499-29) is in the very fine clay to medium silt size range $(11<\phi<5,0.48 \mu \mathrm{m}<$ diameter $(d)$ $<32 \mu \mathrm{m}$ ), with greater than $80 \%$ in the clay to fine silt range $(9<\phi<6)$. The predominant sediment size of the outer shelf (e.g. Station KM-22, KM-24), in contrast, is in the medium sand to granule size range $(3<\phi<-1,0.125 \mathrm{~mm}<d<2.4 \mathrm{~mm})$, with greater than $80 \%$ in the medium to coarse sand range $(2<\phi<0)$. The size distributions of the outer shelf sediment show a tailing effect, skewing toward the fine-grained sizes. Most inner and outer shelf sediments display a normal grain size distribution. Away from the Yangtze River Delta, the middle shelf sediments display a bimodal size distribution (e.g. Station 499-17, Fig. 3) and rapidly prograding to a normal distribution toward the outer shelf. The bimodal appearances of sediment grain sizes indicated that sediments in the middle shelf were composed of a mixture between the fine-grained Yangtze River sediment and the coarse-grained relict sediments.

\subsection{Carbonate content}

Carbonate was most abundant on the outer continental shelf (Fig. 2B). The highest concentration, up to $90 \%$, was found in the southeastern part of the study area where the Kuroshio Current intruded onto the East China Sea continental shelf. Carbonate contents between $10 \%$ and $30 \%$ were common on the shelf; and values greater than $25 \%$ were observed mostly in areas directly under the path of the Kuroshio Current. Most sediments were biogenic carbonate along the southeastern part of the outer shelf. The Kuroshio Current flowing along the outer shelf break area appears to act as a barrier for the deposition of fine-grained terrigenous sediments on the outer shelf. Carbonate concentration and distribution pattern are similar to those observed by Niino and Emery (1961).

\subsection{Organic carbon}

The distribution of organic carbon in the East China Sea continental shelf sediments also showed a "band-type" distribution pattern (Fig. 2C). In general, the organic carbon concentrations decreased seawards, reflecting a corresponding increase of the sediment grain size (Fig. 2A) and proportion of marine organic material. High concentrations of organic carbon were found in the Delta and inner shelf areas, with more than $0.9 \%$ of organic carbon found in areas where fine-grained sediments exceeded $70 \%$. Except the Delta and inner shelf region, the organic carbon concentrations were between $0.0 \%$ and $0.4 \%$ for the majority of the East China Sea continental shelf sediments. The organic carbon concentration in the East China Sea continental shelf sediments is lower than those observed in other shelf and delta

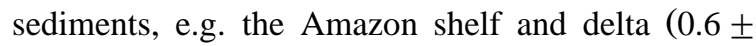
$0.1 \%$, Aller et al., 1986), the Mississippi shelf and delta $(0.71 \pm 0.27 \%$, Lin and Morse, 1991), and the world shelf average $(0.75 \%$, Berner, 1982). In addition, less than $0.2 \%$ of organic carbon were found in the outer shelf areas where approximately $90 \%$ of the sediments were composed of coarse-grained quartz and/or carbonate sand. Lower concentrations of organic carbon observed in the middle and outer continental shelf sediments is probably a combined result of limited fine-grained sediment deposition and rapid organic carbon oxidation in sediments through sulfate reduction as demonstrated by Lin et al. (2000).

Organic carbon in the Delta and inner shelf sediments were composed primarily of terrigenous material where $\delta \mathrm{C}^{13}$ were as low as $-25 \%$ o. $\delta \mathrm{C}^{13}$ of the organic carbon increased linearly with decreasing organic carbon concentration (Fig. 4D). Away from the Delta and inner shelf, the organic carbon concentration decreased rapidly since fewer terrigenous organic matters were capable of transporting and depositing on the middle and outer shelf area. Subsequently, $\delta \mathrm{C}^{13}$ of the organic carbon rapidly changed 


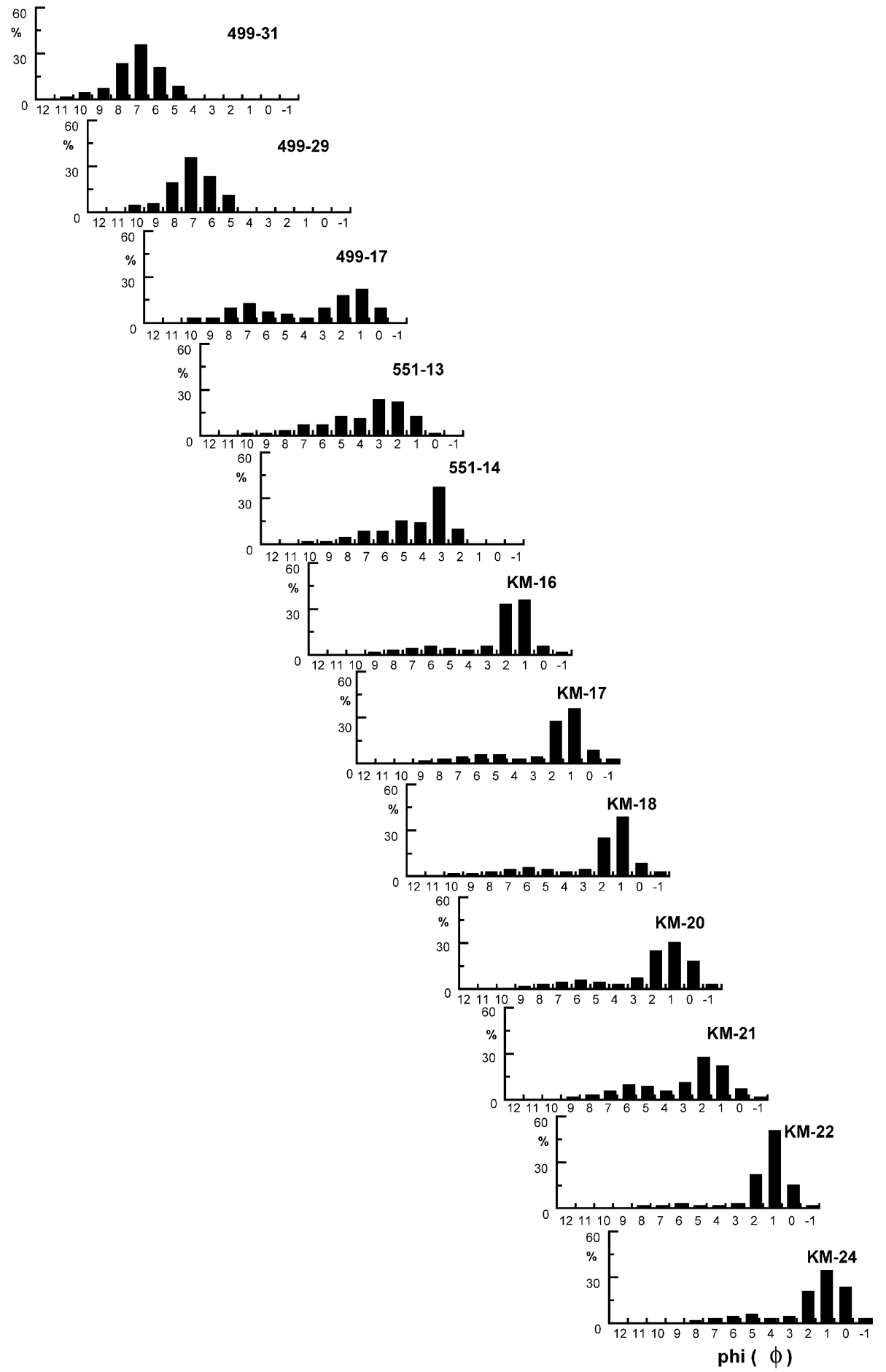

Fig. 3. Grain size variations from Station 31 (near the Yangtze River) to 24 (shelf break). See Fig. 1 for station locations. 

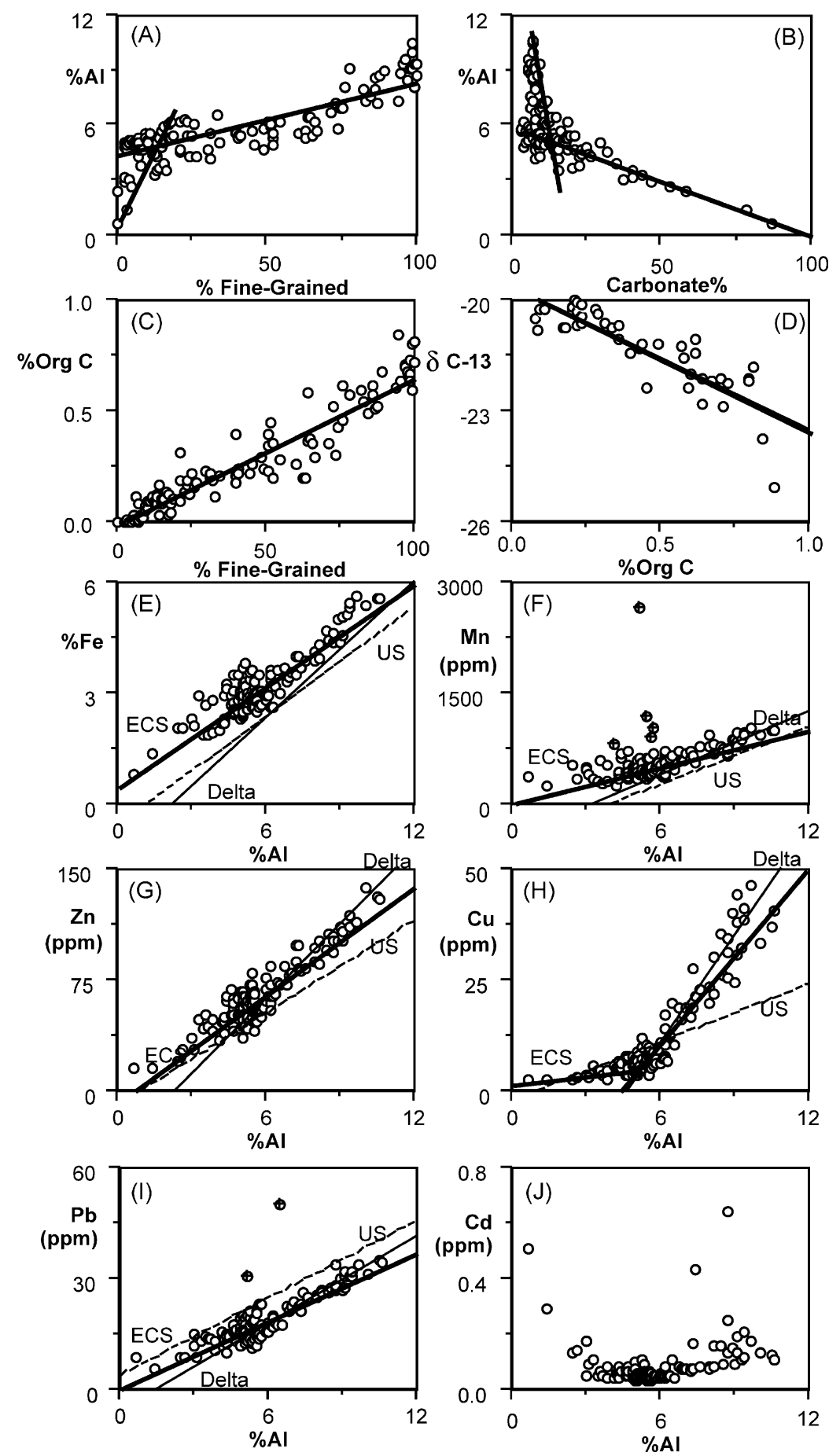

Fig. 4. Relationships between the concentrations of $\%$ Aluminum, and $\%$ Fine-grained sediment, \%carbonate, $\%$ organic carbon, $\delta \mathrm{C}^{13}$, Fe, $\mathrm{Mn}, \mathrm{Zn}, \mathrm{Cu}, \mathrm{Pb}, \mathrm{Cd}$ of the East China Sea continental shelf sediment $(\mathrm{O})$. Wide lines are the linear regression of the ECS data. Thin line is the Yangtze River Delta sediment data from Liao et al (1990). Dotted line is the Southeast U.S. coastal sediment data from Windom et al. (1989). $\oplus$ : Data not included in the linear regression. 
to predominant marine $(\sim 20 \%$ ) in origin. This variation resembled those described by Tan et al. (1991) where $\delta \mathrm{C}^{13}$ of the Yangtze River Deltaic sediments were as low as $-26.4 \%$. Similar rapid change of organic carbon $\delta \mathrm{C}^{13}$ from terrestrial to marine was also observed in the Amazon River Delta (Showers and Angle, 1986) and the Mississippi River Delta (Sackett and Thompson, 1963).

\section{4. $\mathrm{Al}, \mathrm{Fe}, \mathrm{Mn}, \mathrm{Zn}, \mathrm{Cu}, \mathrm{Pb}$}

Similar to the sand\%, organic carbon concentrations and $\delta \mathrm{C}^{13}$ content, surface sediment aluminum, iron, manganese, zinc, copper and lead concentrations also displayed a "band-type" distribution pattern with concentration decreasing seaward (Fig. 2). Heavy metal concentrations decreased more rapidly in the seaward (west-east) direction than those in the southward direction, especially those near the Delta.

Aluminum concentrations (Fig. 2D) in the East China Sea continental shelf sediments were in the range of $0.7-11$ wt.\%. High concentrations of aluminum were found in the inner shelf region extending from the Yangtze River Delta to the southern end of the study area. Aluminum concentrations decreased seaward from the highest $(11 \%)$ in sediments near the Delta to the lowest $(0.7 \%)$ in the southeastern region with high carbonate contents. An exception to this seaward decreasing trend was the area located in the northeast of the study region where a slightly higher aluminum concentration was found.

Iron concentrations also displayed a "Band-type" distribution (Fig. 2E), with concentrations in between $0.83 \%$ and $5.6 \%$. The lowest iron $(0.3 \%)$ was observed in an area where high concentration of carbonate was also observed (Figs. 2B,E and 4). Iron concentrations $(5.0-5.6 \%)$ in sediments near the Delta and the inner shelf were higher than all other areas in the East China Sea continental shelf.

Manganese concentration (Fig. 2F) displayed slight variations from other metals. Even though high manganese concentrations $(\sim 1000 \mathrm{ppm})$ were still observed in the inner shelf sediments and lower concentrations $(\sim 260 \mathrm{ppm})$ were observed in the outer shelf sediments, an unusually high concentration of manganese (up to $2670 \mathrm{ppm}$ ) was found in the middle shelf region near the Delta.

Zinc (Fig. 2G) and lead (Fig. 2I) displayed a similar band-type distribution pattern in the study area. Up to $137 \mathrm{ppm}$ of $\mathrm{Zn}$ and $50 \mathrm{ppm}$ of lead were found in the inner shelf sediments, especially those near the Delta region. Both metals generally decreased seaward. As low as $16 \mathrm{ppm}$ of zinc and 6 ppm of lead were found in the outer shelf sediments. Lead, however, showed an unusually high concentration $(\sim 50 \mathrm{ppm})$ in the middle shelf region near the Delta.

Similarly, copper (Fig. 2H) also displayed a band-type distribution with a high concentration (46 $\mathrm{ppm})$ in the Delta region and a low concentration $(2.6 \mathrm{ppm})$ in the outer shelf region.

\section{5. $C d$}

Cadmium concentration appeared to decrease from the Delta and inner shelf to the outer shelf. Superimposed on the band-type distribution that was often observed in the heavy metals of the East China Sea continental shelf sediments, cadmium distribution showed two distinct high concentration regions that differed from others. High concentrations of cadmium were observed in the southeastern end of the study shelf break region and the inner shelf region south of the Delta (Fig. 2J). Compared to a low cadmium concentration of approximately 30 to 60 ppb that was commonly observed in the middle shelf and outer shelf sediments, more than $500 \mathrm{ppb}$ of cadmium were found in these two regions.

\section{Discussion}

The distributions of heavy metals, grain size, organic carbon and $\delta \mathrm{C}^{13}$ of the organic carbon provide a solid data base to examine the extent of the influence of the Yangtze River on the East China Sea continental shelf sediment. The distributions of $\mathrm{Al}, \mathrm{Fe}, \mathrm{Mn}, \mathrm{Cu}, \mathrm{Zn}, \mathrm{Pb}, \mathrm{Cd}$, \%sand, \%organic carbon and \%carbonate contents all displayed a large spatial variation in the East China Sea continental shelf sediments, especially in a seaward direction away from the Delta. In particular, a band-type distribution along the coast south of the Yangtze River Delta with high concentrations in the inner shelf and low concentrations in the outer shelf sediments were observed. The most important factors controlling the spatial variations of metals in the East China Sea continental shelf include: sediment sources, grain size, and anthropogenic pollution. 


\subsection{Sediment sources}

Terrigenous sediment from the Yangtze River is a major factor controlling the observed spatial variations. East China Sea continental shelf can be divided into five major regions of sediments: the Delta, inner shelf, middle shelf, outer shelf and northeast outer shelf based on spatial distributions, metals / aluminum ratios, grain size, carbonate, organic carbon contents and $\delta \mathrm{C}^{13}$ of the organic carbon (Table 1). Each area is characterized by metals / aluminum ratio, grain size, carbonate and organic carbon content. The major types of sediments include the terrigenous sediments from the Yangtze River, relict sediment of the middle shelf, biogenic carbonate of the outer shelf and sediments from the Yellow Sea.

High concentrations of heavy metals observed near the Yangtze River and their band-type distributions along the inner shelf south of the Delta demonstrated that the primary source of heavy metals entering the East China Sea continental shelf is from the Yangtze River. With its high suspended sediment concentration of $\sim 540 \mathrm{mg} / 1$ (Shen et al., 1983) and an extremely high water discharge of $\sim 30,000 \mathrm{~m}^{3} / \mathrm{s}$ (Cai, 1982), the Yangtze River is undoubtedly a dominating source of sediment on the shelf. Most sediments were temporarily deposited near the river mouth and later redistributed southward along the inner shelf by the Changjiang Coastal Current (DeMaster et al., 1985). As a result, band-type distributions were observed along the coast south of the Delta. Sediments of the Yangtze River Delta and inner shelf were composed of fine-grained terrigenous clay with high concentrations of heavy metals. Since fine-grained sediments were primarily deposited in the Delta and inner shelf, heavy metal concentrations decreased more rapidly in the seaward direction than those southward along the coast. Similarly, heavy metal concentrations also displayed a band-type distribution in the inner shelf sediments. Delta and inner shelf sediments were characterized by high $\mathrm{Zn} / \mathrm{Al}, \mathrm{Cu} / \mathrm{Al}, \mathrm{Pb} / \mathrm{Al}, \mathrm{Cd} / \mathrm{Al}$ ratios and high concentrations of organic carbon with low $\delta \mathrm{C}^{13}$, indicating a predominant terrigenous sediment with the Yangtze River as the primary source. The variations between Delta and inner shelf were mostly a result of grain-size differences, especially in the vicinity of the Delta where large grain-size variations were observed.

Relict sediment is the predominant type of sediments on the middle and outer shelf region. Niino and Emery (1961) first defined these sediments as relict in origin based on their grain size distribution, shape, and degree of weathering. Fine-grained modern Yangtze River sediments were mostly limited to the inner shelf area, whereas the medium to coarsegrained quartz sand was the main type of sediment in the middle and outer shelf. The area is characterized by the relict coarse-grained quartz sand with low concentrations of metals, organic carbon (Figs. 2A and 3) as well as low metals / aluminum ratios (Table $2)$. The mixture between the modern inner shelf fine-grained sediments and outer shelf relict coarsegrained quartz sand made the metal distribution progressively decrease seaward. The area is also a transition zone from a detrital sediments dominated inner shelf to a biogenic sediment dominated outer shelf.

Biogenic carbonate (Fig. 2B) is the major type of sediment in the outer shelf, especially in the region where the Kuroshio Current intrudes onto the East China Sea continental shelf. Contrary to other sediments of the East China Sea, up to $87 \%$ and no less than $15 \%$ of carbonate are found directly underneath the path of Kuroshio Current. Almost no fine-grained sediments from the Yangtze River are deposited on the outer shelf and the biogenic carbonate is the predominant type of sediments under the path of the Kuroshio. The fine-grained terrigenous sediments were either limited to depositing on this region of the shelf by the Kuroshio Current or were horizontally transported to the slope region (Narita et al., 1990). These biogenic carbonate sediments are characterized by high $\mathrm{Mn} / \mathrm{Al}, \mathrm{Fe} / \mathrm{Al}, \mathrm{Cd} / \mathrm{Al}$ and low $\mathrm{Cu} / \mathrm{Al}$ ratios (Table 2).

The northeast region of the study area is probably an extension of the Yellow Sea. In comparison with the coarse-grained relict sediment commonly found in the outer shelf region, sediments in the northeast region were composed mostly of fine-grained with relatively high concentrations of heavy metals (Table 2). The metal/aluminum ratios in this region also differed significantly from other East China Sea shelf sediments. Relatively high concentrations of heavy metals, especially zinc, copper and manganese resembled sediment in the Yellow Sea north of the 
Table 1

Major deposition areas, sediment $\mathrm{Fe} / \mathrm{Al}, \mathrm{Mn} / \mathrm{Al}, \mathrm{Zn} / \mathrm{Al}, \mathrm{Cu} / \mathrm{Al}, \mathrm{Pb} / \mathrm{Al}, \mathrm{Cd} / \mathrm{Al}$ ratios, \%Sand content and their characteristic features of the East China Sea continental shelf

\begin{tabular}{|c|c|c|c|c|c|c|c|c|c|}
\hline $\begin{array}{l}\text { Deposition } \\
\text { area }\end{array}$ & $\begin{array}{l}\text { Sediment } \\
\text { source }\end{array}$ & $\%$ Sand & $\mathrm{Fe} / \mathrm{Al}$ & $\mathrm{Mn} / \mathrm{Al}$ & $\mathrm{Zn} / \mathrm{Al}$ & $\mathrm{Cu} / \mathrm{Al}$ & $\mathrm{Pb} / \mathrm{Al}$ & $\mathrm{Cd} / \mathrm{Al}$ & Characteristic features \\
\hline Deltaic & $\begin{array}{l}\text { Yangtze } \\
\text { River }\end{array}$ & $<10$ & $0.544(0.026)$ & $93.2(9.29)$ & $11.7(0.81)$ & $3.85(0.675)$ & $3.34(0.197)$ & $0.024(0.018)$ & $\begin{array}{l}\text { Fine-grained terrigenous sediments, } \\
\text { low } \delta \mathrm{C}^{13} \text {, high organic carbon, } \\
\mathrm{Cu} / \mathrm{Al}, \mathrm{Pb} / \mathrm{Al} \text { and } \mathrm{Cd} / \mathrm{Al} \text { ratio. }\end{array}$ \\
\hline Inner shelf & & $10<\%<30$ & $0.529(0.030)$ & $94.2(9.91)$ & $11.8(0.85)$ & $3.34(0.702)$ & $3.26(0.197)$ & $0.018(0.014)$ & \\
\hline Middle Shelf & Relict & $30<\%<90$ & $0.545(0.082)$ & $95.0(29.5)$ & $11.1(1.45)$ & $1.48(0.522)$ & $3.09(0.430)$ & $0.011(0.004)$ & $\begin{array}{l}\text { Medium- to coarse-grained } \\
\text { quartz sand, low } \mathrm{Cu} / \mathrm{Al}, \mathrm{Pb} / \mathrm{Al} \text { and } \\
\mathrm{Cd} / \mathrm{Al} \text { ratio. }\end{array}$ \\
\hline Outer Shelf & Biogenic & $>90$ & $0.663(0.166)$ & $124(94.4)$ & $11.3(2.97)$ & $1.13(0.590)$ & $3.59(1.94)$ & $0.047(0.141)$ & $\begin{array}{l}\text { Coarse-grained biogenic carbonate } \\
\text { sediments, high } \mathrm{Fe} / \mathrm{Al}, \mathrm{Mn} / \mathrm{Al} \text {, } \\
\mathrm{Cd} / \mathrm{Al} \text { ratio, high } \delta \mathrm{C}^{13} \\
\text { low organic carbon. }\end{array}$ \\
\hline $\begin{array}{l}\text { Northeast } \\
\text { Outer Shelf }\end{array}$ & Yellow Sea & $<30$ & $0.547(0.008)$ & $98.1(9.72)$ & $13.2(0.618)$ & $2.63(0.128)$ & $3.09(0.258)$ & $0.011(0.001)$ & $\begin{array}{l}\text { Silty sediments, high } \mathrm{Zn} / \mathrm{Al} \text { and } \\
\text { low } \mathrm{Pb} / \mathrm{Al}, \mathrm{Cd} / \mathrm{Al} \text { ratio. }\end{array}$ \\
\hline
\end{tabular}

Numbers in parentheses are $1 \sigma$ of the metal/Al ratios for each area. 
Table 2

Correlation coefficient $\left(r^{2}\right)$ matrix of $\mathrm{Al}, \mathrm{Fe}, \mathrm{Mn}, \mathrm{Zn}, \mathrm{Cu}, \mathrm{Pb}, \mathrm{Cd}, \%$ Fine-grained sediments, \%Organic carbon and $\delta \mathrm{C}^{13}$ of the organic carbon for the East $\mathrm{China} \mathrm{Sea}$ continental shelf sediments

\begin{tabular}{|c|c|c|c|c|c|c|c|c|c|c|}
\hline & $\mathrm{Al}$ & $\mathrm{Fe}$ & $\mathrm{Mn}$ & $\mathrm{Zn}$ & $\mathrm{Cu}$ & $\mathrm{Pb}$ & $\mathrm{Cd}$ & $\begin{array}{l}\text { \%Organic } \\
\text { carbon }\end{array}$ & $\delta \mathrm{C}^{13}$ & $\%$ Carb. \\
\hline$\overline{\mathrm{Al}}$ & 1 & & & & & & & & & \\
\hline $\mathrm{Fe}$ & $0.831(0.456)$ & 1 & & & & & & & & \\
\hline $\mathrm{Mn}$ & $0.635(80.1)$ & $0.790(184)$ & 1 & & & & & & & \\
\hline $\mathrm{Zn}$ & $0.857(12.2)$ & $0.826(24.2)$ & $0.634(0.102)$ & 1 & & & & & & \\
\hline $\mathrm{Cu}$ & $\begin{array}{l}\mathrm{A} 1 \%>5 \%: \\
0.903(7.22) \\
\mathrm{A} 1 \%<5 \%: \\
0.365(0.928)\end{array}$ & all: $0.802(10.8)$ & $0.750(0.052)$ & $0.753(0.395)$ & 1 & & & & & \\
\hline $\mathrm{Pb}$ & $0.841(3.10)$ & $0.772(6.03)$ & $0.667(0.027)$ & $0.746(0.224)$ & $0.759(0.497)$ & 1 & & & & \\
\hline $\mathrm{Cd}$ & $0.035(0.0087)$ & $0.062(0.023)$ & $0.119(0.00014)$ & $0.057(0.00084)$ & $0.199(0.0034)$ & $0.102(0.0043)$ & 1 & & & \\
\hline \%Org. C & $0.737(0.113)$ & $0.643(0.211)$ & $0.652(0.0011)$ & $0.674(0.0081)$ & $0.852(0.00201)$ & $0.673(0.0031)$ & $0.110(0.95)$ & 1 & & \\
\hline$\delta \mathrm{C}^{13}$ & $0.652(-0.500)$ & $0.702(-0.859)$ & $0.651(-0.0045)$ & $0.649(-0.0031)$ & $0.795(-0.071)$ & $0.578(-0.122)$ & $0.639(-17.5)$ & $\begin{array}{l}0.665 \\
(-3.85)\end{array}$ & 1 & \\
\hline$\%$ Carb. & $\begin{array}{l}\text { Carb\% > 20: } \\
0.741(-0.059) \\
\text { Carb\% < 20: } \\
0.006(-0.51)\end{array}$ & $\begin{array}{l}\text { all: } 0.220 \\
(-0.0032)\end{array}$ & $0.143(-5.85)$ & $0.220(-0.827)$ & $0.132(-0.295)$ & $0.245(-0.229)$ & $\begin{array}{l}\text { Carb\% > 20: } \\
0.672(0.0036) \\
\text { Carb\% < 20: } \\
0.000(0.0009)\end{array}$ & $\begin{array}{l}0.179 \\
(-0.0075)\end{array}$ & $\begin{array}{l}0.029 \\
(0.057)\end{array}$ & 1 \\
\hline $\begin{array}{l}\text { \%Fine- } \\
\text { grained } \\
\text { sediments }\end{array}$ & $\begin{array}{l}\% \text { Fine }>25: \\
0.710(0.0412) \\
\% \text { Fine }<25: \\
0.724(0.310)\end{array}$ & $\begin{array}{l}\text { all: } 0.577 \\
(0.020)\end{array}$ & $0.590(4.20)$ & $0.602(0.545)$ & $0.774(0.282)$ & $0.575(0.137)$ & $0.083(0.0005)$ & $\begin{array}{l}0.913 \\
(0.0068)\end{array}$ & $\begin{array}{l}0.454 \\
-0.026)\end{array}$ & $\begin{array}{l}0.216 \\
(-0.192)\end{array}$ \\
\hline
\end{tabular}

Numbers in parentheses are the slope of the linear regressions. 
study region where copper, manganese and zinc were high (Kim et al., 1998).

\subsection{Grain size}

Grain size is also a major factor controlling the spatial variations of the heavy metals and organic carbon in the East China Sea continental shelf sediments (Fig. 4). Similar spatial distribution patterns were observed for metals and organic carbon with respect to the percentage of fine-grained sediments in the East China Sea continental shelf sediments (see Fig. 2). The inner shelf was dominated by fine-grained terrigenous sediments, whereas the middle and outer shelf were mostly composed of coarse-grained relict quartz and/or biogenic carbonate sand. Quartz as well as carbonate sand were the two most important dilution components for the observed grain-size effect on the sedimentary metal concentration variations (Fig. 4). Quartz and carbonate sand consisted of silica and carbonate with relatively little heavy metals and contained almost no organic carbon, both served as diluting materials for heavy metals from aluminosilicate minerals (i.e. clays) and organic matter of biogenic origin. With increasing percentage of fine-grained sediments (grain size $<63 \mu \mathrm{m}$ ) and decreasing proportion of carbonate content, aluminum concentrations increased accordingly (Fig. 4A,B). The percentage of fine-grained sediments and carbonate content showed a good correlation with respect to the aluminum content (Fig. 4A,B and Table 2). The slope of the correlation, however, changed from 0.0412 to 0.310 for sediments with less than $25 \%$ of fine-grained sediments, and from -0.0585 to -0.508 for sediments with less than $20 \%$ of carbonate content. The changing slope represented a shift in dilution effect from quartz to carbonate on the aluminum concentration of the aluminosilicate minerals.

Corresponding to the grain-size effect on the aluminum concentration, the organic carbon (Fig. 4C), iron (Fig. 4E), manganese (Fig. 4F), zinc (Fig. 4G), copper (Fig. 4H), and lead (Fig. 4I) also showed a strong grain-size control effect. Table 2 presents the linear regression of the data. The positive linear correlation between metals and aluminum indicated that terrigenous aluminosilicate minerals are the primary metal bearing minerals with the exception of cadmium. In addition, the occurrences of a high organic carbon concentration in the Deltaic and inner shelf sediments and the low $\delta \mathrm{C}^{13}(-25 \%)$ further demonstrated that the inner shelf and Deltaic sediments were composed of materials primarily terrigenous in origin (Fig. 4D). With the increasing aluminum concentration, i.e. more fine-grained sediments, sediment metal concentrations also increased correspondingly with the exception of cadmium for the studied metals. The metal-rich aluminosilicate are associated with the fine-grained fraction of sediments. Variation of grain-size distribution is one of the most important factors influencing the spatial variations of natural metal concentrations on the East China Sea continental shelf.

Previous studies have demonstrated that grain-size was a major factor controlling sedimentary heavy metal concentrations (Zhao and Yan, 1993; Windom et al., 1989; Cauwet, 1987; Horowitz and Elrick, 1987; Zhao, 1985; deGroot et al., 1982; Mayer and Fink, 1980; Forstner and Salomons, 1980). As a comparison, data from the Southeast U.S. coastal sediments (Windom et al., 1989) and the Yangtze River Delta (Liao et al., 1990) were also plotted in Fig. 4E-I. Not surprisingly, most heavy metals showed a good linear relationship with respect to the aluminum concentration. With a few exceptions, the heavy metal/aluminum relationships of this study resemble the data obtained from the Yangtze River delta sediments by Liao et al. (1990), but a sharp contrast to the Southeast U.S. coastal sediments which displayed a rather large deviation. Differences in metal/aluminum correlation between the East China Sea continental shelf and the Southeast U.S. coastal sediments were probably resulted from differences in source rocks, weathering history and clay mineral assemblages. Since Liao et al. (1990) showed that heavy metals in sediments were originated from the upstream Yangtze River, the similarities clearly suggested that the Yangtze River is the primary source of aluminosilicate minerals and that the distribution of the fine-grained aluminosilicate minerals on the shelf determined the spatial variations of heavy metal concentrations.

A number of manganese, lead, cadmium and especially copper concentrations, however, showed significant variations from the linear metal/ aluminum relationships. Zhang (1999) indicated that 
waste drainage from the Huangpujiang, a tributary of the Yangtze River near Shanghai city, might have increased the suspended sediment metal concentrations by $50-100 \%$. Huh and Chen (1999) demonstrated that anthropogenic pollution was the cause of rapid lead concentration increase in the East China Sea inner shelf sediments. Consequently, the occurrences of high concentrations of lead, cadmium, manganese observed in some parts of the inner shelf area seemed to indicate that a second source of metals, most likely anthropogenic in origin, may have entered the inner shelf region and drastically increased their concentrations. The areas where higher $\mathrm{Pb}, \mathrm{Mn}$ and $\mathrm{Cd}$ concentrations were observed were mostly located in or near the inner shelf. Deposition of these anthropogenic metals may differ from those natural metal bearing fine-grained aluminosilicate minerals and subsequently deviate from the observed grain-size controlled metal/aluminum relationships.

Unusual copper concentrations observed in the inner shelf and Delta sediments also indicated a possibility of pollution. Unlike other heavy metals, copper concentrations increased exponentially with increasing aluminum concentrations $\left(r^{2}=0.842\right)$. Copper/aluminum relationship of the inner shelf sediments was clearly different from that of the middle and outer shelf sediments. For the inner shelf and Delta sediments, however, copper concentrations increased linearly with aluminum concentration with an intercept at $-32\left(r^{2}=0.903\right.$, Table 2) with a slope that differed from the middle and outer shelf sediment. For the middle and outer shelf sediments, copper and aluminum concentrations showed a rather limited association with a coefficient of 0.365 (Table 2). Delta and inner shelf sediments were recently deposited, whereas the middle and outer shelf sediments were mostly relict from the last glacial (Huh and Su, 1999; DeMaster et al., 1985). As a result, the unusual increase of copper concentrations of the Delta and inner shelf sediments may either be a result of the recent industrialization in the Yangtze River drainage basin as suggested by Zhang (1999) or a change of copper carrying phase in the Delta region. In addition to the aluminosilicate, other phases such as organic carbon or iron oxide could be another important contributor to the unusual copper concentrations increase in the Delta and inner shelf sediments. However, the fact that both iron and organic carbon correlated well with the aluminum and that copper concentration increased rapidly in cores (see discussion below) indicated that anthropogenic source(s) from recent industrial development in the Delta region may be responsible for the unusual increase of copper.

Cadmium is another exception to the observed metal/aluminum relationship. Its distribution on the East China Sea continental shelf seems to deviate from most other metals since high $\mathrm{Cd}$ concentrations were located in the outer shelf area as well as in the inner shelf region. Thus, a lack of linear correlation with respect to aluminum indicated that aluminosilicate minerals are not the major types of natural metal bearing phases in the East China Sea sediments. Even though the inner shelf high $\mathrm{Cd}$ concentrations may be related to an anthropogenic origin, the occurrences of high $\mathrm{Cd}$ concentration on the outer shelf were by no means anthropogenic as well. High concentrations of cadmium observed in the outer shelf region were found in sediments with high carbonate contents. Cadmium concentration increased linearly with carbonate content for sediments with greater than $25 \%$ of carbonate $\left(r^{2}=0.672\right.$, Table 2). The correlation between $\mathrm{Cd}$ and carbonate content indicated that $\mathrm{Cd}$ is probably associated with biogenic carbonate production in the outer shelf. Cadmium is a nutrient type metal being removed from surface water by plankton growth (Bruland, 1983). In addition, Hester and Boyle (1982) demonstrated that cadmium in the foraminifera test represented the chemical composition of the water they grow in. The shoaling of Kuroshio Current in the outer shelf region of the East China Sea probably provided cadmium and subsequently sequestered away by the biogenic carbonate and resulted in a cadmium-enriched carbonaceous sediment near the outer shelf.

\subsection{Historical changes and implication}

Unusual spatial distribution of copper as well as lead and cadmium in sediments near the Delta and inner shelf indicated that anthropogenic source(s) may become an important factor controlling heavy metal concentrations in the East China Sea inner shelf sediments. Vertical heavy metal concentration 
variations in deep sediment cores were examined in order to evaluate the level of pollution and/or diagenetic remobilization and to establish background concentrations and historical changes of heavy metals in sediments. Vertical profiles of heavy metal concentration and metal/aluminum ratio at Station 16 (Delta) and Station 9 (inner shelf away from the Delta) are presented in Fig. 5. Also plotted are the 1987 time markers for both cores calculated with sedimentation rates from Huh and $\mathrm{Su}$ (1999).

Deposition of heavy metals in sediments showed clear historical changes, especially during the past two decades. Large vertical heavy metal concentration variations for both cores were observed, especially the heavy metal enrichment at the surface (Station 9) or near surface (Station 16). From the concentration maximum, heavy metal concentrations decreased rapidly with increasing depth, while below a depth of approximately $30 \mathrm{~cm}$, metal concentrations as well as metal/aluminum ratios showed very little variations. Low metal concentrations in the top $6 \mathrm{~cm}$ of Station 16 were a result of grain size change.
At depth, sediments were mostly fine-grained, whereas sand size grain was predominant in the top few centimeters. After normalization by the aluminum content, the metal/aluminum ratios decreased rapidly from the surface with increasing depth.

Vertical variations were also influenced by the distance from the Yangtze River. Higher concentrations of heavy metal concentrations were observed deeper in sediments near the Delta than those away from the Delta. In Station 16 near the Delta, higher heavy metals concentrations and ratios could extend deeper into cores (approximately $30 \mathrm{~cm}$ ) and gradually leveling off at depth. In Station 9 further away from the Delta, only surface enrichments $(\sim 4 \mathrm{~cm})$ were observed. In addition, except manganese and zinc, heavy metal concentrations and ratios at depth in Station 16 were higher than those at depth in the Station 9. Surface sediment metal enrichments were about $30 \%(\mathrm{Cu}), 26 \%(\mathrm{~Pb}), 25 \%(\mathrm{Cd}), 10 \%(\mathrm{Zn})$ higher than those at depth calculated using metal aluminum ratios for Station 16. Further south in
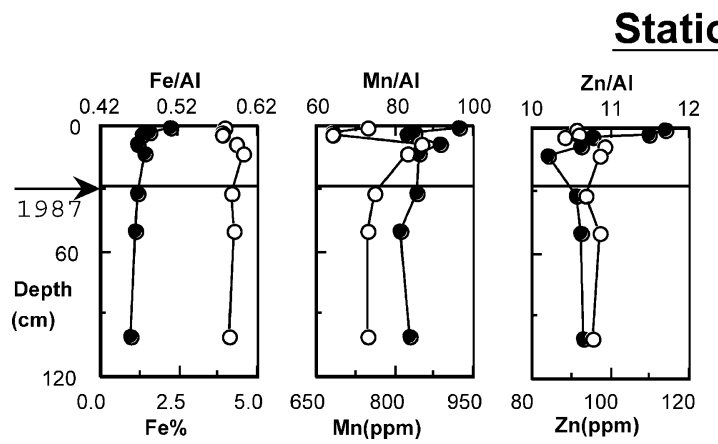

\section{6}
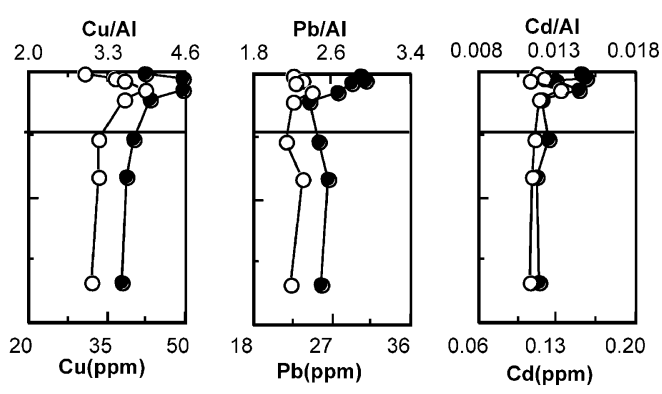

\section{Station 9}
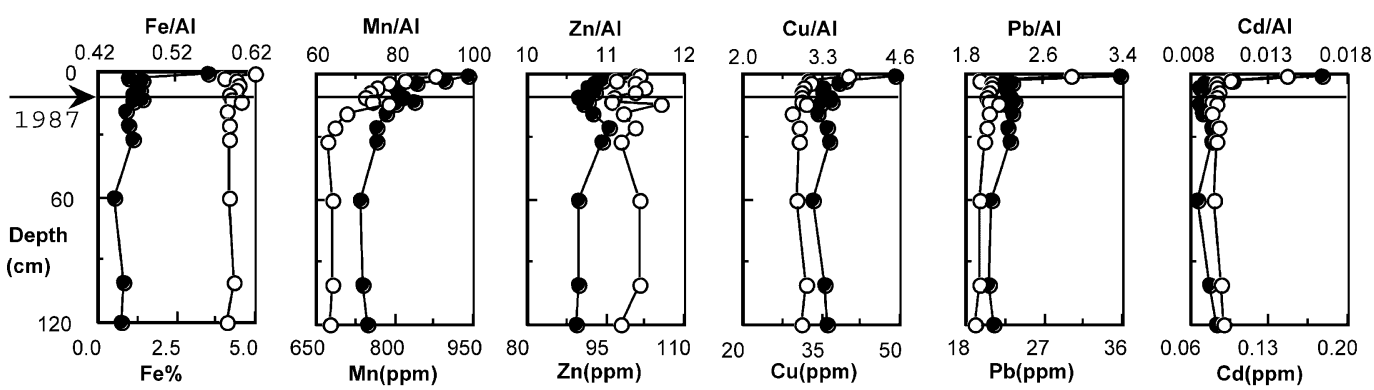

Fig. 5. Vertical variations of $\mathrm{Fe}, \mathrm{Mn}, \mathrm{Zn}, \mathrm{Cu}, \mathrm{Pb}, \mathrm{Cd}$ and $\mathrm{Fe} / \mathrm{Al}, \mathrm{Mn} / \mathrm{Al}, \mathrm{Zn} / \mathrm{Al}, \mathrm{Cu} / \mathrm{Al}, \mathrm{Pb} / \mathrm{Al}, \mathrm{Cd} / \mathrm{Al}$ in Stations 16 and $9 . \mathrm{Open}$ circles (O) are metal concentrations and filled circles (O) are metal/aluminum ratios. See Fig. 1 for locations of Stations 16 and 9. 
Station 9, some of the surface sediment metal enrichments (e.g. $60 \%$ for $\mathrm{Pb}$ and $\mathrm{Cd}$ ) were higher than those in Station 16. However, these higher enrichments were only observed in the top $4 \mathrm{~cm}$ and less than $10 \%$ of the enrichments were found in the entire core below the top $4 \mathrm{~cm}$.

Manganese vertical variations, however, were not directly related to an accessory anthropogenic supply in these cores. Both manganese concentrations and $\mathrm{Mn} / \mathrm{Al}$ ratio showed a much deeper enrichment than other metals. Similar to that observed in the Long Island Sound sediment (Aller, 1980), surface manganese enrichment is a result of diagenetic remobilization. Under a reducing condition, pore water manganese increased during sediment manganese oxide reduction (Aller, 1980; Stumm and Morgan, 1981). Surface maximum is often observed as pore water manganese diffusion and reprecipitation at the sediment/water interface.

The profound increase of heavy metals in sediment vertical profiles and their spatial distributions demonstrated that, to a large extent, the rapid industrialization since the opening of China in 1972 is most likely the culprit in alternating the "natural" heavy metal deposition in the East China Sea continental shelf sediment. The increase of metal concentrations in the Yangtze River Delta sediment showed the most drastic vertical changes. In addition, nearly the entire inner shelf sediments are showing signs of rapid change. Copper, lead, and cadmium all showed unusual rapid increase especially during the past decade. The extent of this increasing trend is quite alarming since the entire inner shelf is most likely at risk from a river drainage basin heavily populated and rapidly industrialized with little practice of pollution regulatory. Proper pollution prevention measures are needed to prevent further degradation of the East China Sea inner shelf.

\section{Conclusions}

Yangtze River is the major terrigenous sediments source that determined the concentrations of heavy metals and organic carbon variations on the East China Sea continental shelf. Large variations of heavy metals, grain size, carbonate, organic carbon concentrations and $\delta \mathrm{C}^{13}$ of the organic carbon reflect the spatial variations in the proportions of terrigenous and biogenic components deposited on the East China Sea continental shelf and their mixtures with the relict sediment. In addition, unusual high concentrations of copper, lead, and cadmium found in the sediments of the Yangtze River Delta and inner shelf indicated possible anthropogenic influences from the recent rapid economic growth in China.

Source, grain size and anthropogenic influence are the major factors that controlled metals and organic carbon spatial and vertical concentration variations in the East China Sea continental shelf sediments. Major types of sediments include the terrigenous Yangtze River sediments of the Delta and inner shelf, the relict sediments of the middle and outer shelf, biogenic carbonate of the outer shelf and sediments from the Yellow Sea. The distributions of metals, grain size as well as the organic carbon all showed a similar band-type pattern of spatial variations with higher concentrations in the inner shelf and Delta sediments and lower concentrations in the outer shelf sediments. Stable carbon isotope $\delta \mathrm{C}^{13}$ in sediments near the Delta indicated a predominately terrigenous source, whereas sediments away from delta were characterized by organic carbon with marine signature.

Metals and organic carbon concentrations in sediments were also controlled by the grain sizes in addition to reflect relative proportions of different type of sediments. Heavy metals and organic carbon linearly increased with increasing proportions of fine-grained sediments. Fine-grained sediments from the Yangtze River were deposited mostly in the inner shelf and Delta and decreased rapidly away from land. As a result, metals and organic carbon concentrations also decreased in a seaward direction.

Near surface rapid increases of metal concentrations were observed in vertical profiles. The depth where rapid increase of metal concentrations were observed was deeper in site near the Delta, whereas high concentrations of metals were only observed in surface sediments approximately 200 miles away from the Delta.

Unusually high concentrations of $\mathrm{Cu}, \mathrm{Pb}$, and $\mathrm{Cd}$, both spatially and vertically, showed that more pollution prevention measures are needed in the Yangtze River drainage basin in order to prevent further heavy metal pollution of the East China Sea inner continental shelf. 


\section{Acknowledgements}

The authors thank the anonymous reviewers and the Editor for their constructive suggestions. We thank captains and crews of $\mathrm{R} / \mathrm{V}$ "Vinogradov" and "Ocean Researcher-I" for their efforts during the sample collections. We also like to thank Dr. MingPen Chen for his efforts in organizing the KEEPMASS cruise and Mr. Chin-Ming Chen and In-Tian Lin for their elegant analytical works in the lab.

\section{References}

Aller, R.C., 1980. Diagenetic processes near the sediment-water interface of Long Island Sound: II. Fe and Mn. Adv. Geophys. 22, 351-415.

Aller, R.C., Mackin, J.E., Cox Jr., R.T., 1986. Diagenesis of Fe and $\mathrm{S}$ in Amazon inner shelf muds: apparent dominance of $\mathrm{Fe}$ reduction and implications for the genesis of ironstones. Cont. Shelf Res. 6, 263-289.

Berner, R.A., 1982. Burial of organic carbon and pyrite sulfur in the modern ocean: its geochemical and environmental significance. Am. J. Sci. 282, 451-473.

Boutton, T.W., 1991. Stable carbon isotope ratios of natural materials: sample preparation and mass spectrometric analysis. In: Coleman, D.C., Fry, B. (Eds.), Carbon Isotope Techniques. Academic Press, San Diego, pp. 155-171.

Bruland, K.W., 1983. Trace elements in sea-water. In: Riley, J.P., Skirrow, G. (Eds.), Chemical Oceanography, vol. 8. Academic Press, London, pp. 157-220.

Cai, A.Z., 1982. Diffusion of sediments of Changjiang River discharging into the sea. Acta Oceanol. Sin. 4, 78-87.

Cauwet, G., 1987. Influence of sedimentological features on the distribution of trace metals in marine sediments. Mar. Chem. 22, 221-234.

deGroot, A., Shuppe, K., Salomons, W., 1982. Standardization of methods of analysis for heavy metals in sediments. Hydrobiology 92, 689-695.

DeMaster, D.J., McKee, B.A., Nittrouer, C.A., Qian, J.C., Chen, G.D., 1985. Rates of sediment accumulation and particle reworking based on radiochemical measurements from continental shelf deposits in the East China Sea. Cont. Shelf Res. 4, 143-158

Folk, R.L., 1974. Petrology of Sedimentary Rocks. Hemphill Pub., Texas, 129 pp.

Forstner, U., Salomons, W., 1980. Trace metal analysis on polluted sediments: I. Assessment of sources and intensities. Environ. Technol. Lett. 1, 494-505.

Hester, K., Boyle, E., 1982. Water chemistry control of cadmium content in recent benthic foraminifera. Nature 298, 260-262.

Horowitz, A., Elrick, K., 1987. The relation of stream sediment surface area, grain size, and composition to trace element chemistry. Appl. Geochem. 2, 437-451.
Huh, C.-A., Chen, H.-Y., 1999. History of lead pollution recorded in East China Sea sediments. Mar. Pollut. Bull. 38, 545-549.

Huh, C.-A., Su, C.-C., 1999. Sedimentation dynamics in the East China Sea elucidated from $210 \mathrm{~Pb}, 137 \mathrm{Cs}$ and $239,240 \mathrm{Pu}$. Mar. Geol. 160, 183-196.

Kim, G., Yang, H.S., Kodama, Y., 1998. Distributions of transition elements in the surface sediments of the Yellow Sea. Cont. Shelf Res. 18, 1531-1542.

Kokot, S., King, G., Keller, H.R., Massart, D.L., 1992. Application of chemometrics for the selection of microwave digestion procedures. Anal. Chim. Acta 268, 89-94.

Lee, H.J., Chough, S.K., 1989. Sediment distribution, dispersal and budget in the Yellow Sea. Mar. Geol. 87, 195-205.

Liao, X., Chen, Z., Ying, S., Fan, A., Zhang, X., Wei, L., Ren, D., Gao, S., 1990. The sources and the geochemical characteristics of the heavy metals in the sediment of the Changjiang River and its adjacent coastal waters of the East China Sea. In: Yu, G., Martin, J.M., Zhou, J., Windom, H., Dawson, R. (Eds.), Biogeochemical Study of the Changjiang Estuary, Proceedings of the International Symposium on Biogeochemical Study of the Changjiang Estuary and its Adjacent Coastal Waters of the East China Sea. China Ocean Press, Beijing, pp. 413-436.

Lin, S., Morse, J.W., 1991. Sulfate reduction and iron sulfide mineral formation in Gulf of Mexico anoxic sediments. Am. J. Sci. 291, 55-89.

Lin, S., Huang, K.M., Chen, S.K., 2000. Organic carbon deposition and its control on iron sulfide formation of the Southern East China Sea continental shelf sediments. Cont. Shelf Res. 20, 619-635.

Luo, Y., Ostenso, N.A., 1983. Sedimentation on the Continental Shelf, with Special Reference to the East China Sea. China Ocean Press, Beijing, 952 pp.

Mayer, L.M., Fink, K.J.R., 1980. Granulometric dependence of chromium accumulation in estuarine sediments in Maine. Estuarine Coastal Mar. Sci. 11, 491-503.

McKee, B.A., Nittrouer, C.A., DeMaster, D.J., 1983. Concepts of sediment deposition and accumulation applied to the continental shelf near the mouth of the Yangtze River. Geology 11, 631-633.

Milliman, J.D., Meade, R.H., 1983. World-wide delivery of river sediment to the oceans. J. Geol. 91, 1-21.

Milliman, J.D., Syvitski, J.P.M., 1992. Geomorphic/tectonic control of sediment discharge to the ocean: the importance of small mountainous rivers. J. Geol. 100, 525-544.

Milliman, J.D., Qhen, H.-T., Yang, Z.-S., Meade, R.H., 1985. Transport and deposition of river sediment in the Changjiang estuary and adjacent continental shelf. Cont. Shelf Res. 4, $37-45$.

Narita, H., Harada, K., Tsunogai, S., 1990. Lateral transport of sediment particles in the Okinawa Trough determined by natural radionuclides. Geochem. J. 24, 207-216.

Niino, H., Emery, J.O., 1961. Sediments of shallow portions of East China Sea and South China Sea. Geol. Soc. Am. Bull. 72, 731-762.

Sackett, W.M., Thompson, R.R., 1963. Isotopic organic carbon composition of recent continental derived clastic sediments of eastern gulf coast, Gulf of Mexico. Bull. Am. Assoc. Pet. Geol. 47, 525-538. 
Shen, H., Li, J., Zhu, H., Han, M., Zhou, F., 1983. Transport of suspended sediments in the Changjiang estuary. In: Luo, Y., Ostenso, N.A. (Eds.), Sedimentation on the Continental Shelf, with Special Reference to the East China Sea. China Ocean Press, Beijing, pp. 389-399.

Showers, W.J., Angle, D.G., 1986. Stable isotopic characterization of organic carbon accumulation on the Amazon continental shelf. Cont. Shelf Res. 6, 227-244.

Stumm, W., Morgan, J.J., 1981. Aquatic Chemistry. Wiley, New York.

Tan, F.C., Cai, D.L., Edmond, J.M., 1991. Carbon isotope geochemistry of the Changjiang estuary. Estuarine, Coastal Shelf Sci. 32, 395-403.

Windom, H.L., Schropp, S.J., Calder, F.D., Ryan, J.D., Smith Jr., R.G., Burney, L.C., Lewis, F.G., Rawlinson, C.H., 1989. Natural trace metal concentrations in estuarine and coastal marine sediments of the southeastern United States. Environ. Sci. Technol. 23, 314-320.

Yu, G., Martin, J.M., Zhou, J., Windom, H., Dawson, R., 1990. Biogeochemical Study of the Changjiang Estuary. Proceedings of the International Symposium on Biogeochemical Study of the Changjiang Estuary and its Adjacent Coastal Waters of the East China Sea. China Ocean Press, Beijing, p. 898.

Zhang, J., 1999. Heavy metal compositions of suspended sediments in the Changjiang (Yangtze River) estuary: significance of riverine transport to the ocean. Cont. Shelf Res. 19, 15211543.

Zhao, Y.-Y., 1985. Some geochemical patterns of shelf sediments of the China Sea. Chin. J. Oceanol. Limnol. 3, 200-211.

Zhao, Y.-Y., Yan, M.-C., 1993. Geochemical record of the climate effect in sediments of the China shelf sea. Chem. Geol. 107, 267-269. 